\title{
Análise do estado de cobertura vacinal de crianças menores de três anos no município de Fortaleza em 2017
}

\author{
Analysis of the state of vaccination coverage of children under three years old in the city of \\ Fortaleza in 2017
}

\section{Análisis del estado de cobertura de vacunación de niños menores de tres años de edad en la ciudad de Fortaleza en 2017}

\author{
Joana Angélica Paiva Maciel ${ }^{1}$, Anamaria Cavalcante e Silva² ${ }^{\mathbb{D}}$, Jocileide Sales Campos $^{2} \mathbb{D}$, Luciano Lima Correia ${ }^{3}$, Hermano Alexandre \\ Lima Rocha ${ }^{2,3} \mathbb{D}$, Sabrina Gabriele Maia Oliveira Rocha ${ }^{2,3} \mathbb{D}$, Edgar Gomes Marques Sampaio³ \\ ${ }^{1}$ Secretaria Municipal de Saúde de Fortaleza. Fortaleza, CE, Brasil. \\ ${ }^{2}$ Centro Universitário Unichristus, ISEC. Fortaleza, CE, Brasil. \\ ${ }^{3}$ Universidade Federal do Ceará, Departamento de Saúde Comunitária. Fortaleza, CE, Brasil.
}

\section{Resumo}

Objetivo: Analisar o estado atual da cobertura vacinal (CV) de crianças menores de três anos no município de Fortaleza, CE, e sua relação com a condição socioeconômica das famílias. Métodos: Pesquisa transversal de base populacional com amostragem aleatória. As informações foram obtidas por meio da aplicação de questionários e conferência de Cadernetas de Saúde quanto ao estado vacinal, bem como de dados ecológicos de desenvolvimento humano. A CV foi estimada em crianças na faixa etária de 19 a 36 meses. Resultados: Observou-se que 45,2\% das crianças estudadas apresentavam-se com a CV recomendada pelo Ministério da Saúde (MS). Além disto, verificou-se fatores socioeconômicos determinantes de cobertura vacinal e que áreas descobertas de Agentes Comunitários de Saúde apresentaram pior cobertura. Conclusão: O presente estudo revela que é necessário fortalecer as ações que aumentem as cobertura vacinais no município.

Palavras-chave: Vacinas; Cobertura Vacinal; Programas de Imunização; Saúde da Criança

\begin{abstract}
Objective: To analyze the current state of the vaccination coverage (VC) of children under three years old in the city of Fortaleza, CE, and its relation with the socioeconomic status of the families. Methods: A population-based cross-sectional survey with random sampling, information was obtained through questionnaires applied and Health Booklets conferred to the vaccination status, as well as ecological human development data. VC was estimated in children between the ages of 19 and 36 months. Results: It was observed that $45.2 \%$ of studied children presented a VC recommended by the Ministry of Health. In addition, socioeconomic factors which are determinants of vaccine coverage were identified and that areas not covered by community health agents have worse coverage. Conclusion: The present study reveals that it is necessary to strengthen actions that increase VC in the municipality.
\end{abstract}

Keywords: Vaccines; Vaccination Coverage; Immunization Programs; Child Health

Como citar: Maciel JAP, Silva AC, Campos JS, Correia LL, Rocha HAL, Rocha SGMO, et al. Análise do estado de cobertura vacinal de crianças menores de três anos no município de Fortaleza em 2017. Rev Bras Med Fam Comunidade. 2019;14(41):1824. http://dx.doi.org/10.5712/rbmfc14(41)1824

\section{Autor correspondente: Hermano Alexandre Lima Rocha. E-mail: hermano@ufc.br Fonte de financiamento: Este trabalho foi financiado pela Fundação Cearense de Apoio ao Desenvolvimento Científico e Tecnológico. Edital CHAMADA 07/2013 - PPSUS CE - FUNCAP/SESA/MS/ CNPq. Número do auxílio 13506703-0. Parecer CEP: 2.255.063 (UNICHRISTUS), aprovado em 01/09/2017.}

Procedência e revisão por pares: revisado por pares. Recebido em: 21/07/2018. Aprovado em: 18/12/2018. 


\section{Resumen}

Objetivo: Analizar el estado actual de la cobertura vacunal $(\mathrm{CV})$ de niños menores de tres años en el municipio de Fortaleza y su relación con la condición socioeconómica de las familias. Métodos: Investigación transversal de base poblacional con muestreo aleatorio, se obtuvo información a través de cuestionarios aplicados y Cuadernos de Salud conferidos al estado vacunal, así como datos ecológicos de desarrollo humano. La CV fue estimada en niños en el grupo de edad de 19 a 36 meses. Resultados: Se observó que el 45,2\% de los niños estudiados se presentaban con la CV recomendada por el Ministerio de Salud. Además, que factores socioeconómicos son determinantes de cobertura vacunal y que áreas descubiertas de agentes comunitarios de salud presentan peor cobertura. Conclusión: El presente estudio revela que es necesario fortalecer las acciones que aumenten las CV en el municipio.

Palabras clave: Vacunas; Cobertura de Vacunación; Programas de Inmunización; Salud del Niño

\section{Introdução}

A cobertura vacinal (CV) é o "Percentual de crianças imunizadas com vacinas específicas, em determinado espaço geográfico, no ano considerado", conforme ficha do indicador da Rede Interagencial de Informação para Saúde (Ripsa). ${ }^{1}$ Para alcançar uma CV adequada, são necessárias ações institucionais consonantes e organizadas pelo setor público, em todos os níveis. O controle da CV é importante para o monitoramento do quantitativo de suscetíveis na população-alvo, além de ser um indicador da saúde infantil e do alcance dos serviços, embasando o processo de planejamento e reestruturação das ações de vacinação. ${ }^{2}$

Segundo o Ministério da Saúde, os indicadores devem levar em consideração as doses completas de vacinação para cada doença, ou seja, a aplicação de todas as vacinas preconizadas pelo Programa Nacional de Imunizações (PNI). ${ }^{3}$ O monitoramento da CV é uma tarefa imprescindível para a avaliação dos programas de vacinação, pois permite analisar, geográfica e temporalmente, as variações nas proporções de crianças menores de um ano de idade vacinadas com cada tipo de imunizante recomendado pelo PNI. ${ }^{3}$ O Ministério da Saúde preconiza as metas percentuais de CV de rotina, sendo $95 \%$ de cobertura para o protocolo básico de vacinação para menores de um ano de idade. ${ }^{4}$

No entanto, vale ressaltar que a estimativa da CV tem algumas limitações, podendo ocorrer erros que dificultam aferir o percentual exato da população coberta em determinada situação, devido à presença de valores médios elevados, que podem omitir indivíduos com baixa cobertura em determinados grupos populacionais, comprometendo o monitoramento e controle das doenças.

Podem ocorrer dos registros imprecisos de doses de vacina aplicadas, principalmente durante a realização de campanhas de vacinação, inclusive devido ao aumento da demanda da população não nativa aos postos de vacinação, o que dificulta a correta avaliação da CV. Ou, ainda, a base de dados demográficos da qual se estima o número de crianças menores de um ano de idade pode conter imprecisões especialmente em anos intercensitários. ${ }^{5}$ Por isso, desde a criação do $\mathrm{PNI}$, pesquisas e inquéritos domiciliares têm sido realizados, a fim de monitorar as coberturas vacinais e avaliar o cumprimento das metas estabelecidas, entre as quais, está o alcance de $100 \%$ das crianças com menos de um ano de idade, com todas as vacinas do esquema básico de vacinação. ${ }^{6}$

No início da década de 1980, os indicadores básicos de saúde infantil e de coberturas dos serviços no Ceará eram desatualizados, indisponíveis ou pouco confiáveis. Como exemplo, não havia um indicador 
de parâmetro para se estimar a taxa de mortalidade infantil no Estado. Assim, em 1987, decidiu-se, por iniciativa governamental, realizar um diagnóstico basal do estado de saúde da população materno infantil. Para isso, dois dos mais renomados epidemiologistas do país, César Victora e Fernando Barros, da Universidade Federal de Pelotas, foram convidados pelo UNICEF a delinear, junto com a equipe de pediatras, a primeira Pesquisa Estadual de Saúde Materno Infantil do Ceará (PESMIC).

Considerando o cenário anteriormente exposto, especialmente no tocante às vulnerabilidades na definição das coberturas vacinais, surgiu na instituição gestora da saúde municipal de Fortaleza a necessidade de conhecer, de forma mais precisa, a realidade. Por isso, decidiu-se extrair da PESMIC 2017 os dados referentes à CV de crianças até três anos, residentes no município, tendo em vista que os resultados encontrados a partir de inquéritos domiciliares, ao serem mais precisos, farão com que a gestão municipal da saúde possa atuar de forma mais assertiva, na busca por melhores coberturas vacinais, o que reduzirá o risco de se surpreender com a recrudescência de doenças imunopreveníveis há muito afastadas da realidade epidemiológica do município.

O objetivo deste estudo foi analisar o estado da cobertura vacinal de crianças menores de três anos no município de Fortaleza em 2017 e sua relação com a condição socioeconômica das famílias, representada pelo Índice de Desenvolvimento Humano (IDH) e a renda familiar mensal; o nível de escolaridade e a idade da mãe; além de relacionar a adesão à vacinação e a residência da criança em área coberta pela atuação dos Agentes Comunitários de Saúde (ACS).

\section{Métodos}

Os dados do presente estudo provêm da PESMIC VI, um inquérito epidemiológico do tipo transversal, realizado no ano de 2017. Nesta pesquisa de base populacional, foram obtidas informações sobre mulheres em idade fértil (de 10 a 49 anos), seus filhos menores de 6 anos e suas respectivas famílias.

$\mathrm{Na}$ PESMIC de 2017, os domicílios em que residiam crianças de 0 a 6 anos de idade (incompletos) perfaziam um total de 3.200 residências, destas, 960 localizavam-se no município de Fortaleza, correspondendo a $30 \%$ da amostra total. Para garantir a representatividade da população estudada, a seleção dos municípios, setores e domicílios foi realizada de forma aleatória, obedecendo a um processo de amostragem de múltiplos estágios. ${ }^{7} \mathrm{O}$ primeiro indivíduo foi escolhido por meio de sorteio utilizando um número randômico de uma lista hipotética de 1 até o total de habitantes do Ceará, utilizando o site random.org. ${ }^{8}$

O plano amostral seguiu as seguintes etapas: a) Amostragem estratificada, para considerar a proporção populacional da Capital, Fortaleza, e do interior do estado; b) Amostragem por conglomerados, para a seleção dos domicílios dentro do município. Neste último estágio, utilizaram-se os setores censitários do Instituto Brasileiro de Geografia e Estatística (IBGE) (áreas geográficas de extensões variáveis, mas com população uniforme de 300 famílias) para a localização dos conglomerados de 20 casas.

Em Fortaleza, utilizando-se a lista de setores censitários fornecida pelo IBGE, foram sorteados 48 setores, garantindo-se que todas as áreas da cidade, mesmo as mais periféricas, pudessem ser representadas. Uma vez sorteado o setor, e seu respectivo mapa obtido do IBGE, foi determinada, por sorteio, a localização do conglomerado de 20 casas a serem pesquisadas dentro do setor, utilizando-se, para tanto, o software ArcGis, na versão 10.1 . 
Em seguida, novamente de forma aleatória, foi determinado o ponto de partida do conglomerado, ou seja, o primeiro domicílio a ser visitado, sendo estabelecido que, nas áreas urbanas, necessariamente, seria um cruzamento, sorteando-se as coordenadas possíveis dentro do setor. Em cada domicílio, todas as mulheres e crianças nas faixas etárias da pesquisa nele residentes tiveram seus respectivos questionários aplicados e suas 'Cadernetas de Saúde' conferidas.

Depois de concluída a coleta de dados no primeiro domicílio, o trabalho de campo prosseguia, seguindo regras específicas: a) O pesquisador visitava as casas obedecendo ao sentido horário; b) Não eram incluídas no conglomerado de 20 casas os estabelecimentos comerciais e as casas sem moradores, sendo estas substituídas por outras vizinhas; c) No caso de famílias ausentes, até três retornos foram realizados na tentativa de obtenção dos dados do domicílio.

As informações foram coletadas utilizando-se questionário referente à saúde infantil, que foi aplicado a todos os responsáveis pelas crianças com menos de seis anos de idade residentes nos domicílios visitados. Após as entrevistas, foi realizada a aferição da situação vacinal na Caderneta de Saúde da Criança.

Os questionários foram revisados, sistematicamente, pela supervisora de campo para a identificação de erros de preenchimento e sua correção, quando possível. Com o objetivo de conhecer a situação da CV particularmente no município de Fortaleza, foram analisados na amostragem geral os dados específicos deste município.

O presente estudo foi realizado nos meses de julho e agosto de 2017, no município de Fortaleza, sede da capital do Estado do Ceará, e quinta cidade com maior contingente populacional do país, com 2.609.716 habitantes, ${ }^{6}$ distribuídos em sete Secretarias Regionais (I, II, II, IV, V, VI e Regional do Centro).

As variáveis estudadas foram: $\mathrm{CV}$, definida como o percentual de crianças imunizadas com vacinas específicas, em determinado espaço geográfico, no período considerado; ${ }^{1}$ para cada uma das vacinas específicas, somente foi considerada coberta a criança que tivesse tomado todas as doses recomendadas no PNI, e foram consideras com vacinação incompleta crianças com vacinação completa para até seis, das oito seguintes vacinas, não aplicadas ao nascer na maternidade: Antipólio, Pentavalente, Rotavírus, Tríplice Viral, Tetra Viral, Pneumocócica, Meningocócica C e Hepatite A.

Também foram utilizadas a renda familiar em dólares utilizando-se uma taxa de conversão de 3 reais, recebimento de bolsa família, Índice de Desenvolvimento Humano (IDH), conforme aferido pela Secretaria Municipal de Saúde de Fortaleza e fornecido aos pesquisadores, tendo sido utilizada com variável numérica, escolaridade e idade materna e territórios cobertos por ACS, de acordo com pergunta realizada durante o inquérito sobre visita de ACSs no domicílio em questão. A cobertura vacinal foi definida considerando se a criança estudada já havia tomada o número de doses mínimas recomendadas para aquela faixa etária, conforme definido pelo Ministério da Saúde do Brasil.

Os dados foram digitados e processados em microcomputador usando o software Epi Info 2000 (CDC/WHO), sendo utilizado o programa STATA vrs. 13 para a análise estatística. Nesta análise, a situação vacinal das crianças na faixa etária de 19 a 35 meses foi avaliada, considerando-se esta uma faixa em que todas as crianças já deveriam ter recebido todas as doses de cada vacina recomendada, podendo, portanto, serem consideradas como com vacinação completa. Esta faixa de idade é mundialmente aceita em estudos de CV. ${ }^{8}$ 
Variáveis contínuas, como idade materna, foram agrupadas em categorias, quando apropriado. Para todas as variáveis categóricas, testes do Qui-quadrado foram aplicados, para avaliar a significância estatística. O Teste Exato de Fisher foi utilizado nos casos em que pequenas frequências foram observadas. Valores ignorados foram excluídos das análises quando apropriado.

As associações entre os eventos de natureza vacinal (variáveis dependentes principais) e as variáveis independentes foram exploradas por meio da análise bivariada, com o cálculo da Odds Ratio e os respectivos intervalos de confiança a 95\%. Utilizamos o comando Survey do Stata para ajustar a medida de prevalências ao efeito amostral dos conglomerados, e identificamos que não houve interferência nas estimativas de prevalência e nos valores $p$ das associações. Como somente um estrato geográfico foi utilizado nesta análise (Fortaleza), não foi considerado na análise.

Este Projeto de Pesquisa foi aprovado pelo Comitê de Ética em Pesquisa da UNICHRISTUS, em Fortaleza, no dia 1 de setembro de 2017 (Parecer Nº 255 063).

A fonte de financiamento externo não participou de forma alguma no delineamento da pesquisa, na coleta e análise de dados, na decisão de publicar ou na escolha da revista.

\section{Resultados}

O estudo PESMIC em Fortaleza pesquisou ao todo 1.065 crianças de 0 a 72 meses, sendo que destas 616 eram menores de 3 anos, e 272 apresentavam idade entre 19 a 35 meses, a faixa etária escolhida para avaliar o grau de vacinação, proporcionando inclusive uma razoável margem de tolerância para atrasos na aplicação das doses.

Observou-se que apenas duas vacinas (BCG e Tríplice Viral) estão com coberturas consideradas satisfatórias, segundo definição do Ministério da Saúde, que recomenda coberturas superiores a 95\% para o esquema Vacinal Básico do primeiro ano de vida.

A vacina BCG é administrada em dose única ao nascer, enquanto que a vacina Tríplice Viral foi alvo de uma intensificação dos esforços de vacinação, por conta de um surto de sarampo verificado em 2015 em Fortaleza. ${ }^{9}$

A vacina contra hepatite B apresenta uma situação em que mais de $90 \%$ das crianças recebem a primeira dose ao nascer, na maternidade; mas somente $2,2 \%$ se tornam vacinadas, com o recebimento da segunda dose nos serviços de saúde. Vale ressaltar, entretanto, que a proteção contra a hepatite B também é proporcionada pela vacina Pentavalente, que, entretanto, não cobre com as suas 3 doses necessárias cerca de uma a cada quatro crianças. Além da Pentavalente, outras vacinas com mais de $20 \%$ de crianças não vacinadas incluem a Anti-pólio, a Tetra Viral e a Meningocócica C.

Verificou-se uma ótima CV para as vacinas BCG (99,3\%) e Tríplice Viral (95,2\%), alcançando as recomendações do Ministério da Saúde (Tabela 3). Já o percentual de crianças vacinadas contra hepatite A foi de $85,7 \%$, inferior aos $95 \%$ recomendados pelo MS, um índice relativamente fácil de ser alcançado considerando-se que uma única dose a mais é suficiente para alcançar a vacinação recomendada para a criança. Para a Vacina Tetra Viral, encontrou-se um percentual de $80,1 \%$ de cobertura vacinal, índice inferior ao recomendado pelo MS, que é de 95\%. No entanto, vale ressaltar que, com exceção da varicela, as crianças devem estar vacinadas para as demais infecções preveníveis por esta vacina, uma vez que a cobertura da Tríplice Viral é praticamente universal. 
Na Tabela 1 é importante destacar que, entre os 19 e 36 meses de vida, menos da metade das crianças $(45,2 \%)$ apresentavam-se vacinadas para todas, ou praticamente todas, as dez vacinas constantes do Calendário Vacinal preconizado no PNI. Cerca de $20 \%$ das crianças só apresentaram status de vacinadas para até seis das dez vacinas básicas.

Tabela 1. Prevalência de vacinação completa em crianças de 19 a 36 meses, de acordo com o tipo e o número de vacinas - Fortaleza, $2017(\mathrm{~N}=271)$.

\begin{tabular}{lcc}
\hline Especificação & No. & $\%$ \\
\hline Tipos de vacinas: & & \\
\hline BCG & 270 & 99,3 \\
Tríplice Viral & 259 & 95,2 \\
Rotavírus & 234 & 86,0 \\
Hepatite A & 233 & 85,7 \\
Pneumocócica & 229 & 84,2 \\
Tetra Viral & 218 & 80,6 \\
Meningocócica C & 213 & 78,3 \\
Antipólio & 208 & 76,5 \\
Pentavalente & 207 & 76,1 \\
Febre Amarela & 11 & 4,0 \\
Hepatite B & 6 & 2,2 \\
\hline No. de vacinas: & & \\
\hline 9 a 10 vacinas & 123 & 45,2 \\
7 a 8 vacinas & 99 & 36,4 \\
5 a 6 vacinas & 25 & 9,2 \\
3 a 4 vacinas & 17 & 6,3 \\
0 a 2 vacinas & 8 & 2,9 \\
\hline
\end{tabular}

Bacillus Calmette-Guérin (BCG).

Verificou-se um percentual de cobertura completa da vacina contra o Rotavírus de 86\% (Tabela 2). Chama a atenção o fato de que só é preciso aplicar mais uma dose nas crianças que já tiveram acesso à vacina, para se atingir o índice de $95 \%$ de cobertura recomendado pelo MS. Para a vacina Pneumocócica 10 valente, observou-se uma proporção de $84,2 \%$ de crianças com cobertura vacinal completa.

Ressalte-se o fato de que, se os serviços de saúde estimularem a todas as mães que já tiveram acesso à vacina a retornarem para a segunda dose $(11,4 \%)$, o sistema de saúde atingirá uma cobertura de 95,6\%, atendendo às recomendações do Ministério da Saúde. Quanto à vacina Meningocócica C, observou-se um percentual de 78,3\% de cobertura vacinal completa. Ressaltando-se o fato de que se mais uma dose for aplicada às crianças que já tiveram acesso à vacina (17,7\%), Fortaleza atingirá uma cobertura de $96 \%$, atendendo às recomendações do Ministério da Saúde.

Para a vacina Anti-Pólio encontrou-se um percentual de $76,5 \%$ de CV completa (Tabela 2). É preocupante o fato de que $5,5 \%$ das crianças não haviam recebido nenhuma dose da vacina antipólio aos 3 anos de vida, mostrando que será árdua a tarefa de se alcançar a CV de 95\% recomendada pelo MS, considerando-se a situação atual. Entre as vacinas aplicadas de rotina nos serviços de saúde, a Pentavalente é a que apresenta menor cobertura, com somente $76 \%$ das crianças apresentando-se com vacinação completa na faixa etária analisada, superando somente a vacina contra a Hepatite $B$. 
Tabela 2. Percentual de crianças de 19 a 36 meses vacinadas, por tipo de vacina e o número de doses recebidas - Fortaleza, $2017(\mathrm{~N}=271)$.

\begin{tabular}{|c|c|c|c|c|}
\hline Doses Vacinas & Nenhuma dose & 1 dose & 2 doses & Vacinação Completa \\
\hline \multicolumn{5}{|c|}{ Vacinas com vacinação em dose única: } \\
\hline $\mathrm{BCG}$ & 0,7 & - & - & 99,3 \\
\hline Tríplice Viral & 4,8 & - & - & 95,2 \\
\hline Hepatite A & 14,3 & - & - & 85,7 \\
\hline Tetra Viral & 19,9 & - & - & 80,1 \\
\hline \multicolumn{5}{|c|}{ Vacinas com vacinação em duas doses: } \\
\hline Rotavírus & 5,2 & 8,8 & - & 86,0 \\
\hline Pneumocócica & 4,0 & 11,4 & - & 84,2 \\
\hline Meningocócica C & 4,0 & 17,7 & - & 78,3 \\
\hline \multicolumn{5}{|c|}{ Vacinas com vacinação em três doses: } \\
\hline Antipólio & 5,5 & 11,0 & 7,0 & 76,5 \\
\hline Pentavalente & 4,0 & 9,2 & 10,6 & 76,1 \\
\hline Hepatite B & 4,4 & 91,5 & 1,8 & 2,2 \\
\hline
\end{tabular}

Bacillus Calmette-Guérin (BCG).

Para a vacina Hepatite $B$, verificou-se que somente um percentual ínfimo de $2,2 \%$ das crianças apresentavam as três doses preconizadas desta vacina. Ressalte-se, no entanto, o fato de que $91,5 \%$ das crianças já haviam recebido a primeira dose ao nascer nas maternidades, faltando o retorno aos serviços por parte das mães para as doses subsequentes. É possível, contudo, que a razão da pouca adesão das mães a esta vacina seja o fato de suas crianças já estarem sendo protegidas contra a hepatite $B$ através da vacina Pentavalente.

Com relação à situação econômica da família, a Tabela 3 mostra que para famílias na faixa mais elevada de renda, com ganhos per capita acima de US\$ 5,5 por dia, 40,7\% das crianças não estavam vacinadas para todas as vacinas básicas, um percentual similar ao observado para famílias que vivem numa situação abaixo da linha de extrema pobreza (<US\$1,9), que apresentaram um percentual de $37,7 \%$ de não vacinação.

Quanto à participação no Programa Bolsa Família, chama a atenção o fato de 35,9\% das crianças não estarem vacinadas para todas as vacinas básicas. No tocante à faixa etária, as mães não adolescentes apresentaram um percentual maior de filhos não vacinados $(31,7 \%)$, do que as mães adolescentes $(23,1 \%)$. Com relação à escolaridade materna, constatou-se que $32,1 \%$ dos filhos de mães com ensino médio e superior não foram vacinadas, enquanto que $28,6 \%$ de crianças não vacinadas eram filhos de mães com apenas o ensino fundamental.

Observa-se na Tabela 3 que menos da metade das crianças $(47,2 \%)$ residentes em áreas cobertas por ACS apresentam registros de 9 a 10 vacinas, número muito semelhante ao encontrado nas áreas não cobertas por estes profissionais, que foi de $41,4 \%$.

A Tabela 4 mostra que crianças que vivem em áreas com IDH menor ou igual a 0,19 apresentam $16,7 \%$ de cobertura para até cinco vacinas. Número muito semelhante ao encontrado para aquelas que vivem em áreas com IDH superior a 0,4 , que foi de $17,2 \%$. A cobertura para 9 ou 10 vacinas também mostra semelhança nos extremos de IDH apresentados na Tabela 4. 
Tabela 3. Prevalência de vacinação não completa em crianças de 19 a 36 meses, de acordo com características sócio-econômicas e maternas - Fortaleza, 2017 ( $\mathrm{N}=271)$.

\begin{tabular}{|c|c|c|c|}
\hline \multirow[t]{2}{*}{ Medidas Fatores } & \multirow{2}{*}{$\begin{array}{c}\text { Crianças na amostra } \\
\text { No. (\%) }\end{array}$} & \multirow{2}{*}{$\begin{array}{c}\begin{array}{c}\text { Crianças Não Completamente } \\
\text { Vacinadas }^{1}\end{array} \\
\text { No. (\%) }\end{array}$} & \multirow[t]{2}{*}{ OR (IC95\%) } \\
\hline & & & \\
\hline \multicolumn{4}{|c|}{ Renda familiar mensal per capita: } \\
\hline$<1.9$ USD & $85(32,2)$ & $32(37,7)$ & $2,2(1,1-4,3)$ \\
\hline 2.0 a 3.2 USD & $95(36,6)$ & $27(28,4)$ & $1,4(0,7-3,0)$ \\
\hline 3.3 a 5.5 USD & $55(20,9)$ & $12(21,8)$ & 1 \\
\hline$>5.5$ USD & $27(10,3)$ & $11(40,7)$ & $2,5(0,8-7,5)$ \\
\hline \multicolumn{4}{|c|}{ Participação no Programa Bolsa Família: } \\
\hline Participa & $131(48,2)$ & $47(35,9)$ & $1,5(0,9-2,4)$ \\
\hline Não participa & $141(51,8)$ & $39(27,7)$ & 1 \\
\hline \multicolumn{4}{|l|}{ Idade materna: } \\
\hline Adolescente & $26(9,7)$ & $6(23,1)$ & 1 \\
\hline 20 a 49 anos & $243(90,3)$ & $77(31,7)$ & $1,6(0,6-3,7)$ \\
\hline \multicolumn{4}{|c|}{ Escolaridade materna: } \\
\hline Fundamental & $105(39,8)$ & $30(28,6)$ & 1 \\
\hline Médio/superior & $159(60,2)$ & $51(32,1)$ & $1,2(0,6-2,2)$ \\
\hline
\end{tabular}

${ }^{1}$ Crianças com vacinação completa para até 6 , das 8 seguintes vacinas, não aplicadas ao nascer na maternidade: Anti-pólio, Pentavalente, Rotavírus, Tríplice Viral, Tetra Viral, Pneumocócica, Meningocócica C e Hepatite A.

Tabela 4. Prevalência de vacinação completa em crianças de 19 a 36 meses, de acordo com cobertura da área de residência por Agente Comunitário de Saúde (ACS) e com o Índice de Desenvolvimento Humano (IDH) da área de residência Fortaleza, 2017 ( $\mathrm{N}=271)$.

\begin{tabular}{|c|c|c|c|}
\hline \multirow{3}{*}{$\begin{array}{l}\text { Estado vacinal } \\
\text { Situação da área }\end{array}$} & \multicolumn{3}{|c|}{ Crianças com vacinação completa para: } \\
\hline & 0 - 5 vacinas & 6 - 8 vacinas & 9 - 10 vacinas \\
\hline & No. (\%) & No. (\%) & No. (\%) \\
\hline \multicolumn{4}{|l|}{ Área de residência*: } \\
\hline Coberta por ACS & $20(11,1)$ & $75(41,7)$ & $85(47,2)$ \\
\hline Não coberta por ACS & $10(17,2)$ & $24(41,4)$ & $24(41,4)$ \\
\hline \multicolumn{4}{|l|}{ IDH da área de residência: } \\
\hline$\leq 0,19$ & $12(16,7)$ & $28(38,9)$ & $32(44,4)$ \\
\hline $0,20-0,31$ & $6(9,4)$ & $26(40,6)$ & $32(50,0)$ \\
\hline $0,32-0,41$ & $5(6,9)$ & $35(48,6)$ & $32(44,4)$ \\
\hline$>0,41$ & $11(17,2)$ & $26(40,6)$ & $27(42,2)$ \\
\hline
\end{tabular}

A Figura 1 mostra que crianças que vivem em bairros classificados nos extremos superior (faixa de 0,42 a 0,87 ) e inferior (faixa de 0,12 a 0,19 ) do Índice de Desenvolvimento Humano (IDH) apresentam os níveis mais elevados de não vacinação, quando comparados com crianças que vivem em bairros de IDH intermediário (faixa de 0,20 a 0,41). 

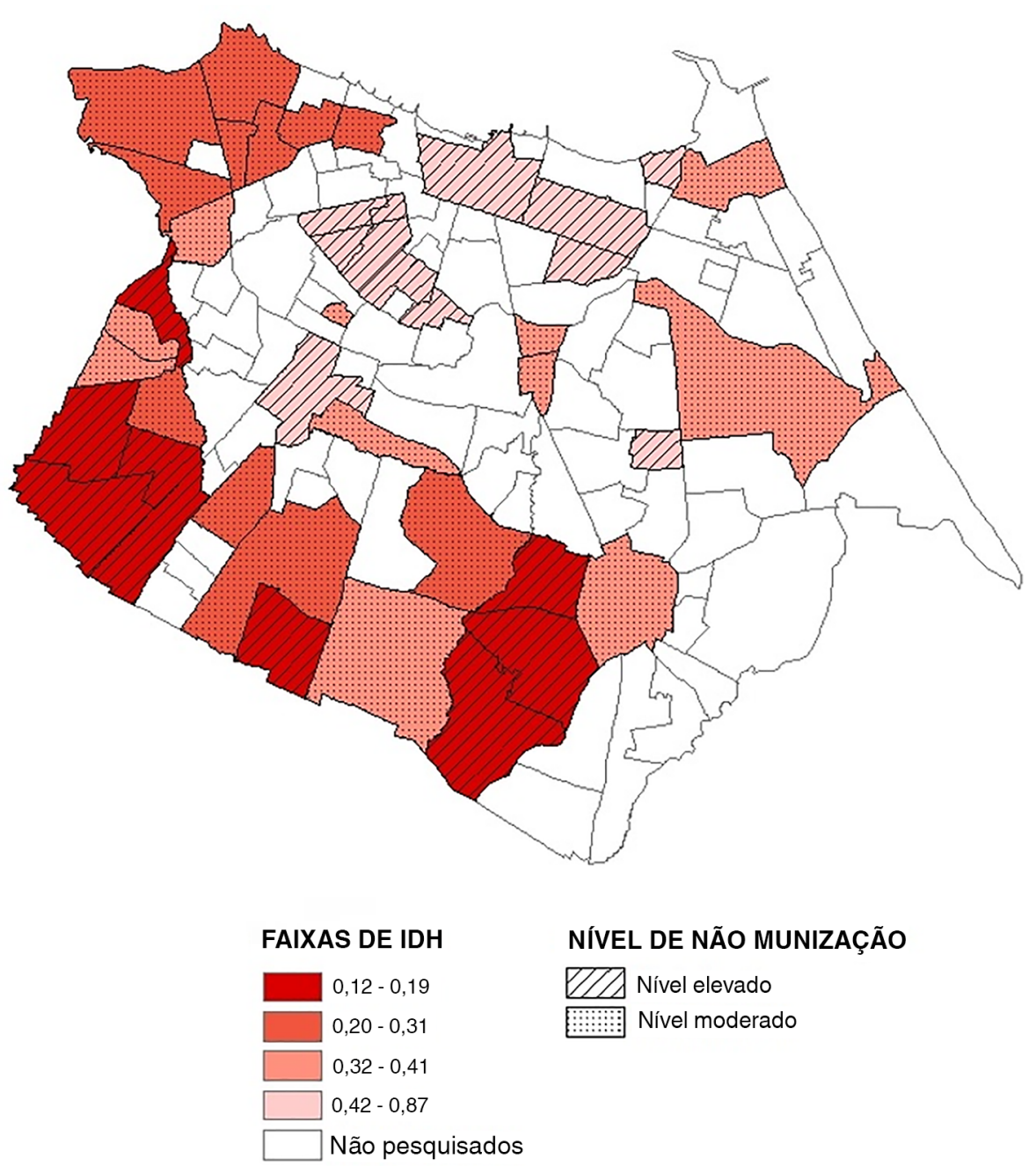

Figura 1. Distribuição espacial dos bairros de acordo com o IDH ${ }^{1}$ e o nível de cobertura vacinal $^{2}$ - Fortaleza, 2017.

\section{Discussão}

Neste estudo, os registros na Caderneta de Saúde da Criança mostraram que apenas para duas vacinas (BCG e Tríplice Viral) encontrou-se o percentual de CV preconizado pelo MS, e que menos da metade $(45,2 \%)$ das crianças pesquisadas tinham tomado 9 ou 10 doses de vacinas na idade recomendada.

Deve-se observar os resultados levando em consideração que os dados do indicador de cobertura vacinal do Datasus informam cobertura vacinal como sendo "constituído pelo número de doses aplicadas (correspondente ao esquema completo de vacinação) de determinado imunobiológico dividido pela população alvo e multiplicado por 100 , em uma área e tempo considerados". ${ }^{3} \mathrm{O}$ uso do número de doses aplicadas, ou utilizadas, pode levar a valores superestimados de cobertura vacinal, o que pode explicar a divergência encontrada com números oficiais. 
A Pesquisa Nacional de Vacinação dos Estados Unidos mostrou que mais de $90 \%$ das crianças estavam atualizadas sobre a vacinação contra poliomielite, hepatite $B$, sarampo, caxumba, rubéola $\mathrm{e}$ varicela. No entanto, as crianças que vivem abaixo do nível de pobreza continuaram a ter menor cobertura de vacina contra rotavírus, vacina pneumocócica conjugada, vacina Haemophilus influenzae tipo b, e vacina contra difteria, tétano e pertusis acelular. ${ }^{8}$

É preocupante o nível encontrado de $76,5 \%$ de crianças vacinadas contra poliomielite, uma vez que o vírus da poliomielite ainda circula em várias regiões do mundo, fazendo que os índices de cobertura dessa magnitude deixem a população vulnerável ao risco de reaparecimento da doença. Em 2017, nasceram 35.110 crianças em Fortaleza, ${ }^{10}$ sendo que, de acordo com os achados do presente estudo, 23,5\% delas não foram vacinadas para poliomielite. Isto leva a crer que 8.250 crianças no referido ano deixaram de ser protegidas contra a doença.

Significa dizer que, se não houver uma enérgica correção dessa situação, haverá um acúmulo a cada ano de crianças não vacinadas, criando grupos de vulneráveis, levando à formação de "bolsões" de risco, aumentando a vulnerabilidade para o retorno dos vírus da Pólio 1 e 3, uma vez que o Pólio Vírus Selvagem Tipo 2 foi declarado erradicado em 20 de setembro de $2015 .^{10}$

A cobertura encontrada para a Vacina Tríplice é satisfatória, com índice de 95,2\% de cobertura. O alcance deste nível, certamente, é responsável por não haver, no município de Fortaleza, nenhum caso confirmado de sarampo ou rubéola desde 2016 e 2009, respectivamente (CEVEP/SMS).

No entanto, vários países europeus convivem, atualmente, com o reaparecimento de casos de sarampo, inclusive o Brasil. ${ }^{11} \mathrm{~A}$ doença afetou 21.315 pessoas, causando 35 mortes em 2017 no continente. ${ }^{12}$ Este fato aponta para baixos índices de CV, mesmo em populações de bom poder aquisitivo.

O presente estudo mostra que, nas famílias de faixa mais elevada de renda, com ganhos per capita acima de US $\$ 5,5$ por dia, $40,7 \%$ de suas crianças não estavam vacinadas para todas as vacinas básicas, um percentual similar ao observado nas famílias que vivem em uma situação abaixo da linha de extrema pobreza (<US\$1,9), que apresentaram um percentual de $37,7 \%$ de não vacinação. Resultado semelhante se observou quando se analisou o IDH, em que há crianças que vivem em áreas com IDH menor ou igual a 0,19 e apresentam $16,7 \%$ de cobertura para até 5 vacinas. Número que é muito semelhante ao encontrado para aquelas que vivem em áreas com IDH superior a 0,4, que foi de $17,2 \%$.

Extremos de idade materna têm sido relatados na literatura como risco para a não vacinação, assim como baixa escolaridade materna, maior número de filhos, maior número de moradores no domicílio, maior ordem de nascimento, mães que trabalham fora do lar, residência há menos de um ano na área, baixo conhecimento sobre as doenças imunopreveníveis, ausência de plano de saúde e presença de doença na criança. ${ }^{13}$ Entretanto, este estudo evidenciou que as mães não adolescentes apresentaram um percentual maior de filhos não vacinados $(31,7)$ do que as mães adolescentes $(23,1)$, o que acreditamos dever-se a maior grau de instrução e menor vulnerabilidade às campanhas de internet e mídias sociais contra a vacinação.

Estudos realizados no Brasil e em outros países têm confirmado o potente efeito da educação materna sobre a educação infantil, em muitas ocasiões, independente até de outras variáveis sociais.

Analfabetismo e status socioeconômico baixo mostraram-se como fatores significativos ligados à menor aceitação da rotina de vacinação contra a poliomielite. ${ }^{14}$ No entanto, no presente estudo, verificou-se 
que $32,1 \%$ dos filhos de mães com ensino médio e superior não foram vacinadas, enquanto $28,6 \%$ de crianças não vacinadas eram filhos de mães apenas com ensino fundamental.

Quanto ao acesso aos profissionais de saúde, alguns estudos demonstraram melhores coberturas vacinais em crianças atendidas por equipes de ESF, enaltecendo o trabalho dos agentes comunitários de saúde na checagem das carteiras de vacina e na busca ativa de crianças faltosas, durante as visitas domiciliares. ${ }^{13}$ Entretanto, neste estudo, observou-se que menos da metade das crianças $(47,2 \%)$ residentes em áreas cobertas por ACSs tem CV completa. Este resultado leva à necessidade de uma urgente sensibilização e capacitação desses profissionais, pois eles têm a condição de fazer busca ativa de todas as crianças não vacinadas, uma vez que atuam realizando visitas domiciliares.

Os resultados do presente estudo apontam para a necessidade de se desenvolver ações que busquem aumentar as Coberturas Vacinais no município de Fortaleza, por meio da sensibilização dos ACSs para a realização de busca ativa de crianças não vacinadas nos territórios, capacitação e sensibilização de todos os profissionais da Estratégia Saúde da Família e da rede suplementar sobre a importância de uma CV satisfatória, estabelecimento de parcerias com operadoras de planos de saúde para buscar uma maior CV na população com um melhor poder aquisitivo.

Sugere-se, também, o envolvimento dos órgãos formadores no sentido de levarem aos acadêmicos da área de saúde mais informações/atividades sobre vacinação, bem como parceria fortalecida para o alcance do propósito de vacinar completamente as crianças e, mesmo, outros grupos etários. Há ainda necessidade de realização de novos estudos com o objetivo de identificar as causas das baixas Coberturas Vacinais.

\section{Limitações}

O presente estudo foi realizado por meio de entrevista direta aos responsáveis pela criança e checagem das cadernetas de saúde, o que pode levar a viés de memória e/ou de registro. Além disso, não foi realizado controle de confundimento das associações apresentadas, mas as variáveis utilizadas são tradicionalmente independentemente associadas com o desfecho.

\section{Contribuição dos autores}

Declaramos que todos os autores tiveram participação de concepção e desenho da pesquisa, obtenção de dados, análise e interpretação dos dados, análise estatística, obtenção de financiamento, redação e revisão crítica do manuscrito quanto ao conteúdo intelectual importante, menos o autor SGMOR, que participou da revisão crítica do manuscrito quanto ao conteúdo intelectual importante.

\section{Conflito de interesses:}

Declaram não haver.

\section{Referências}

1. Teixeira AMS, Rocha CMV. Vigilância das coberturas de vacinação: uma metodologia para detecção e intervenção em situações de risco. Epidemiol Serv Saúde. 2010;19(3):217-26.

2. Oliveira MFS, Martinez EZ, Rocha JSY. Fatores associados à cobertura vacinal em menores de cinco anos em Angola. Rev Saúde Pública. 2014;48(6):906-15. DOI: http://dx.doi.org/10.1590/S0034-8910.2014048005284 
3. Programa Nacional de Imunizações (PNI). Indicador: F 13 Cobertura vacinal. [Internet]. 2006 [acesso 2018 Jan 20]. Disponível em: http:// www.ripsa.org.br/fichasIDB/pdf/ficha_F.13.pdf

4. Carneiro SMMV, Lessa SS, Guimarães JAL, Loepert MM, Silva DB. Cobertura vacinal real do esquema básico para o primeiro ano de vida numa Unidade de Saúde da Família. Rev Bras Med Fam Comunidade. 2012;7(23):100-7.

5. IV - Indicadores universais do rol de diretrizes, objetivos, metas e indicadores: 2013-2015. Guia de apoio à gestão estadual do SU. [Internet]. 2016 [acesso 2018 Mar 30]. Disponível em: http://www.conass.org.br/guiainformacao/category/indicadores-universais-dorol-de-diretrizes-objetivos-metas-e-indicadores-2013-2015-coap/

6. Queiroz LLC. Inquérito domiciliar sobre a cobertura vacinal do esquema básico até o segundo ano de vida [Dissertação de mestrado]. São Luis: Universidade Federal do Maranhão; 2011.

7. Correia LL, Silva AC, Campos JS, Andrade FMO, Silveira DMI, Machado MMT, et al. Metodologia das Pesquisas Populacionais de Saúde Materno-Infantil: uma série transversal realizada no Estado do Ceará de 1987 a 2007. Rev Bras Saude Mater Infant. 2014;14(4):353-62. DOI: http://dx.doi.org/10.1590/S1519-38292014000400005

8. Haahr M. RANDOM. ORG: True Random Number Service. School of Computer Science and Statistics, Trinity College, Dublin, Ireland Website. [acesso 2018 Jan 20]. Disponível em: https://www.random.org/mads/

9. Lemos DR, Franco AR, de Sá Roriz ML, Carneiro AK, de Oliveira Garcia MH, de Souza FL, et al. Measles epidemic in Brazil in the post-elimination period: Coordinated response and containment strategies. Vaccine. 2017;35(13):1721-8. DOI: http://dx.doi.org/10.1016/j. vaccine.2017.02.023

10. Brasil. Ministério da Saúde. Nota informativa № 17-SEI/2017-CGPNI/DEVIT/SVS/MS. Referente à distribuição de imunobiológicos para os estados na rotina do mês de setembro/2017. Brasília: Ministério da Saúde; 2017.

11. Rocha HA, Correia LL, Campos JS, Silva AC, Andrade FO, Silveira DI, et al. Factors associated with non-vaccination against measles in northeastern Brazil: Clues about causes of the 2015 outbreak. Vaccine. 2015;33(38):4969-74. DOI: http://dx.doi.org/10.1016/j. vaccine.2015.07.027

12. Casos de sarampo na Europa aumentam 400\% em um ano. O Globo. 2018. Disponível em: https://oglobo.globo.com/sociedade/saude/ casos-de-sarampo-na-europa-aumentam-400-em-um-ano-22413655

13. Yokokura AVCP, Silva AAM, Bernardes ACF, Lamy Filho F, Alves MTSS, Cabra NAL, et al. Cobertura vacinal e fatores associados ao esquema vacinal básico incompleto aos 12 meses de idade, São Luís, Maranhão, Brasil, 2006. Cad Saúde Pública. 2013;29(3):522-34. DOI: http://dx.doi.org/10.1590/S0102-311X2013000300010

14. Khan MT, Zaheer S, Shafique K. Maternal education, empowerment, economic status and child polio vaccination uptake in Pakistan: a population based cross sectional study. BMJ Open. 2017;7(3):e013853. 